\title{
Rancang Bangun Sistem Informasi Rekam Medis Berbasis Web
}

\author{
Daniel Wahyu Suprayoga Prabowo ${ }^{1}$, Joko Triono ${ }^{2}$ \\ ${ }^{1}$ Program Studi Manajemen Informatika, Universitas Merdeka Madiun, Jl. Serayu No.79, Madiun, 63133 \\ E-mail: daniel@unmer-madiun.ac.id \\ ${ }^{2}$ Program Studi Manajemen Informatika, Universitas Merdeka Madiun, Jl. Serayu No.79, Madiun, 63133 \\ E-mail: jokotriono@unmer-madiun.ac.id
}

\begin{abstract}
A medical officer in conducting health services must make a medical record and must report the medical records to the government hospital or local health department. With these problems in place, this study seeks to build a web-based medical registration system. The system built is expected to be able to accelerate the writing of medical records and provide information to the public wherever and whenever that can be accessed via the internet. Furthermore, in terms of reporting between medical officers and health services faster because medical staff can report the patient's medical record recapitulation through a web-based system, and the health department can print reports on medical records through the system, in addition medical staff can interact with the public by making announcements, health information counseling, and comments relating to medical services.
\end{abstract}

Keywords - : medical records ; information systems; web.

\section{PENDAHULUAN}

Salah satu hal penting dalam sistem pelayanan kesehatan yang prima adalah tersedianya pelayanan medis oleh dokter dan dokter gigi dengan kualitasnya yang terpelihara sesuai dengan amanah Undang-Undang Nomor 29 Tahun 2004 tentang Praktik Kedokteran. Dalam penyelenggaraan praktik kedokteran, setiap dokter dan dokter gigi wajib mengacu pada standar, pedoman dan prosedur yang berlaku sehingga masyarakat mendapat pelayanan medis secara profesional dan aman. Sebagai salah satu fungsi pengaturan dalam UU Praktik Kedokteran yang dimaksud adalah pengaturan tentang rekam medis yaitu pada Pasal 46 dan Pasal 47 (Konsil Kedokteran, 2006).

Perkembangan teknologi informasi yang begitu pesat telah merambah ke berbagai sektor, termasuk kesehatan. Teknologi informasi memiliki potensi dalam memproses data dan mengolahnya menjadi informasi, teknologi informasi mampu menyimpan data dengan jumlah kapasitas lebih banyak. Teknologi informasi juga memungkinkan data kesehatan dikirim secara mudah dan cepat. Perkembangan teknologi informasi sangat mendukung dalam manajemen rekam medis secara lebih efektif dan efisien (Handayani, 2016). Dengan dibuatnya aplikasi sistem informasi manajemen Puskesmas Pakis Baru dapat membantu meringankan pekerjaan petugas Puskesmas agar diperoleh informasi yang cepat dan lebih efisien (Cahyanti, 2012). Pada aplikasi Sistem Informasi Pelayanan Puskesmas Berbasis Web juga bermanfaat dalam media informasi sebagai bentuk perkembangan teknologi dan informasi, meningkatkan efektifitas dan efisiensi dari segi pelayanan, waktu dan biaya pada puskesmas (Sundari, 2016).

Sistem Informasi pencatatan medis kedepannya juga mempermudah dalam kepengurusan klaim asuransi, yaitu apabila pasien memiliki asuransi kesehatan maka untuk pengajuan klaim asuransi pihak instansi asuransi akan meminta data medis dari perawatan kesehatan yang dijalaninya dalam bentuk berkas-berkas beserta formulir pengajuan klaim asuransi ke instansi asuransi, meliputi gejala penyakit, diagnosis, pengobatan, dan tindakan medis yang dilakukan. Hal ini membutuhkan proses yang cukup rumit dan waktu yang cukup lama. Karena selain pasien harus mengurus klaim pengajuan asuransi juga harus mengurus berkas-berkas yang dibutuhkan untuk pengajuan klaim dari instansi medis tempat dia menjalani perawatan, dengan adanya sistem pencatatan medis ini diharapkan memudahkan dalam mengurus berkas-berkas, karena berkas-berkas catatan medis pasien sudah tercatat dalam sistem, dan pihak asuransi tinggal mengakses berkas tersebut (Buliali, 2007).

Pada Sistem Informasi Pencatatan Medis Berdasarkan Kode Penyakit ICD 10 Berbasis Web pada Petugas Medis, seorang petugas medis dalam melakukan pelayanan kesehatan wajib membuat pencatatan medis dan harus melaporkan catatan medis tersebut pada rumah sakit pemerintah atau dinas kesehatan setempat. Penulisan catatan medis diwajibkan menggunakan standart ICD 10 (International Statistical Classification of Diseases and Related Health Problems revisi ke 10) dimana dalam penulisannya sangat rumit karena menggunakan kode-kode tertentu yang memuat banyak nama penyakit dan nama obat sehingga membuat petugas medis kewalahan dalam menjalankan tugasnya. Dengan dibangunnya sistem ini mampu mempercepat penulisan catatan medis dapat membantu kinerja administrasi dalam melakukan pendataan pasien, membantu kinerja petugas medis dalam melakukan pencatatan medis (Prabowo, 2012).

Kondisi petugas medis di Ngawi belum semua mempunyai sistem informasi rekam medis yang dapat membantu dalam mengerjakan tugas pelayanan kesehatan pada seorang petugas medis, Seorang petugas medis dalam melakukan pelayanan kesehatan wajib membuat rekam medis dan harus melaporkan catatan medis tersebut pada rumah sakit pemerintah atau dinas 
kesehatan setempat. Dengan adanya permasalahan tersebut, penelitian ini berusaha membangun sistem pencatatan medis berbasis web. Sistem yang dibangun diharapkan mampu mempercepat penulisan rekam medis dan memberikan informasi pada masyarakat dimanapun dan kapanpun yang dapat diakses melalui internet. Selanjutnya dalam hal pelaporan antara petugas medis dengan dinas kesehatan lebih cepat karena petugas medis dapat melaporkan rekap rekam medis pasien melalui sistem berbasis web, dan dinas kesehatan dapat mencetak laporan catatan medis melalui sistem tersebut, selain itu petugas medis dapat berinteraksi dengan masyarakat dengan cara memberi pengumuman, penyuluhan informasi kesehatan, dan komentar yang berhubungan dengan pelayanan medis.

\section{TINJAUAN PUSTAKA}

\section{A. Pencatatan Medis}

Pencatatan medis atau rekam medis adalah berkas yang berisikan catatan dan dokumen tentang identitas pasien, pemeriksaan, pengobatan, tindakan dan pelayanan lain kepada pasien pada sarana pelayanan kesehatan (Peraturan Menteri Kesehatan Nomor 749a/Menkes/Per/XII/1989), sedangkan menurut penjelasan Pasal 46 ayat (1) UU Praktik Kedokteran yang dimaksud dengan rekam medis adalah berkas yang berisi catatan dan dokumen tentang identitas pasien pada sarana pelayanan kesehatan.

Rekam Medis juga merupakan kompilasi fakta tentang kondisi kesehatan dan penyakit seorang pasien yang meliputi (Gondodiputro, 2007):

1. Data terdokumentasi tentang keadaan sakit sekarang dan waktu lampau.

2. Pengobatan yang telah dan akan dilakukan oleh tenaga kesehatan profesional secara tertulis.

Secara umum, informasi yang tercantum dalam rekam medis seorang pasien harus meliputi (Gondodiputro, 2007):

1. Siapa (Who) pasien tersebut dan Siapa (Who) yang memberikan pelayanan kesehatan/medis.

2. Apa (What), Kapan (When), Kenapa (Why) dan Bagaimana (How) pelayanan kesehatan/medis diberikan.

3. Hasil akhir atau dampak (Outcome) dari pelayanan kesehatan dan pengobatan.

\section{B. Sistem Informasi}

Sistem informasi merupakan seperangkat komponen yang saling terkait yaitu mengumpulkan atau mengambil, memproses, menyimpan, dan mendistribusikan informasi untuk mendukung pengambilan keputusan dan pengontrolan dalam sebuah organisasi (Laudon dan Laudon, 2010).

\section{Framework.NET}

Framework .NET merupakan suatu komponen Windows yang terintegrasi dan dibuat agar dapat menjalankan berbagai macam aplikasi. Framework .NET berisi class librarys untuk menyediakan layanan standar yang dapat diintegrasikan ke berbagai sistem komputer. Framework ini mengatur semua aspek eksekusi program, seperti alokasi memori untuk penyimpanan data dan instruksi, eksekusi aplikasi, izin akses aplikasi, dan re-alokasi memori pada resource yang tidak diperlukan lagi, jadi kesimpulannya Framework .NET adalah lingkungan untuk membangun, deploying/menyebarkan, dan menjalankan services web dan aplikasi lainnya (Kusumo, 2004).

\section{ASP.NET}

ASP.NET adalah kumpulan teknologi dalam Framework .NET untuk membangun aplikasi web dan XML Web Services. Halaman ASP.NET dijalankan di server kemudian akan dibuat halaman markup (penanda) seperti HTML (Hypertext Markup Language), WML (Wireless Markup Language), atau XML (Extensible Markup Language) yang akan dikirim ke browser dekstop atau mobile. Halaman HTML yang dikembalikan dapat juga secara opsional berisi kode script client-side/sisi-client yang akan secara langsung diterjemahkan oleh browser (Kurniawan, 2010).

\section{III.METODE PENELITIAN}

Metode penelitian yang dipakai dalam pengembangan sistem ini adalah waterfall model. Waterfall model adalah suatu model proses untuk memodelkan suatu sistem perangkat lunak yang dibuat secara terstruktur dan berurutan dimulai dari definisi kebutuhan, desain sistem software, implementasi dan testing unit, integrasi dan testing sistem, operasi dan maintance (Pressman, 2012). 


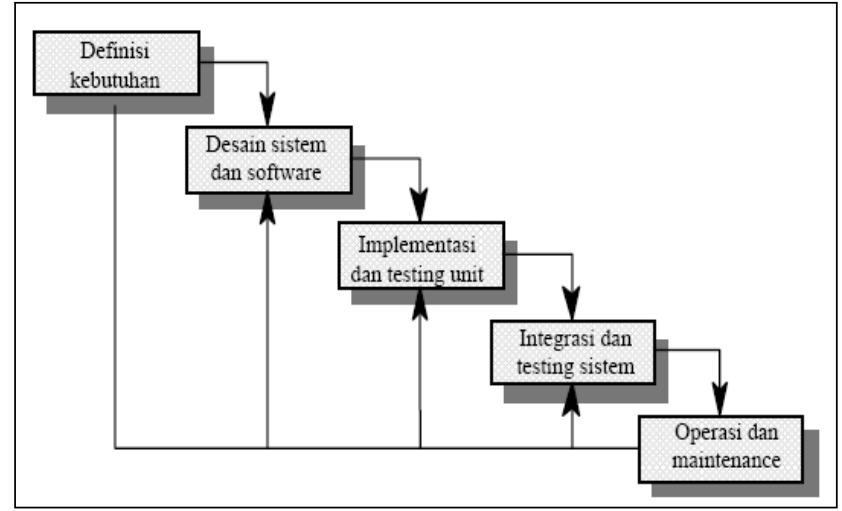

Gambar 1. Bagan Waterfall Model

Tahap-tahap yang dilakukan dalam waterfall model untuk membangun sistem menggunakan ASP.NET dan database Microsoft SQL Server 2008 dalam pengembangan sistem informasi rekam medis berbasis web ini adalah:

\section{Definisi Kebutuhan}

Definisi kebutuhan dilakukan dengan melakukan penelitian di Kabupaten Ngawi, Jawa Timur. Pengumpulan informasi yang pertama dilakukan adalah dengan melakukan wawancara dengan Petugas Medis dan Dokter untuk memeperoleh data tentang rekam medis, kemudian penulis melakukan analisa kebutuhan sistem yang dikembangkan berdasarkan permintaan pengguna sistem.

2. Desain Sistem dan Software

Setelah proses definisi penelitian selesai dan sudah didapatkan informasi yang lengkap, maka tahap selanjutnya adalah melakukan perancangan atau desain sistem yang akan dibuat sesuai dengan hasil penelitian, untuk mendapatkan gambaran sistem yang akan dikembangkan. Desain harus dapat mengimplementasikan kebutuhan yang telah disebutkan pada tahap sebelumnya. Jika pada tahap perancangan ini dilakukan evaluasi dan hasilnya masih belum memenuhi permintaan pengguna, maka akan dirancang kembali sampai permintaan pengguna benar-benar sesuai.

\section{Implementasi dan Testing Unit}

Tahap selanjutnya adalah melakukan implementasi dari rancangan sistem. Implementasi dibuat dengan menggunakan ASP.NET dan database Microsoft SQL Server. Hasil perancangan langsung diuji untuk mengetahui kekurangan atau kesalahan pada sistem yang dibangun.

4. Integrasi dan Testing Sistem

Integrasi sistem diperlukan supaya sistem dapat berjalan seutuhnya dan untuk mengetahui apakah benar-benar memberikan manfaat dalam segi efisiensi dan efektifitas serta memudahkan pengguna dalam pemakaiannya. Pada tahapan ini sistem akan dievaluasi.

\section{Operasi dan Maintance}

Tahap terakhir adalah operasi dan maintance terhadap aplikasi sistem, serta terus mengevaluasi kelemahan-kelemahan yang ada untuk mendapatkan hasil yang maksimal. Pemeliharaan suatu aplikasi diperlukan, termasuk di dalamnya yaitu pengembangan sistem yang dilakukan penyesuaian dengan meningkatnya kebutuhan sistem pada saat diimplementasikan.

\section{IV.HASIL DAN PEMBAHASAN}

\section{A. Perancangan Sistem}

Dalam perancangan sistem ini digunakan Unified Modelling Language (UML). Perancangan dimulai dengan membuat sebuah alur dari model perangkat lunak yang sesuai dengan alur pembuatan aplikasi. Setelah membuat alur atau use case tersebut, maka langkah selanjutnya adalah membuat aplikasi yang sesuai dengan use case yang telah dibuat. Dalam use case diagram ini digambarkan terdapat empat pengguna yaitu administrasi, dokter, pasien dan dinas kesehatan. Administrasi adalah seorang yang bertugas memasukkan data pasien, dokter adalah petugas medis yang memberi layanan kesehatan pada masyarakat yang nantinya akan mencatat setiap kegiatan pelayanan kesehatan, pasien adalah seseorang yang diberi pelayanan medis oleh dokter atau petugas medis, Dinas Kesehatan adalah badan pemerintahan yang mengawasi petugas medis.

Gambar 2 menjelaskan fungsi-fungsi yang dilakukan setiap aktor berbeda, jika seorang pengguna masuk sebagai administrasi maka dia dapat mengelola user, registrasi pasien, input kunjungan, pengumuman, menampilkan report, komentar. Untuk dokter, di sistem tersebut dapat masuk ke dalam komentar, rekam medis pasien, input pembayaran pasien, menampilkan report dan 
Website : http://pilar.unmermadiun.ac.id/index.php/pilarteknologi

pengumuman. Untuk dinas kesehatan dapat masuk ke dalam pengumuman, menampilkan report dan komentar. Sedangkan pasien di dalam sistem dapat melakukan registrasi pasien, pengumuman, dan komentar.

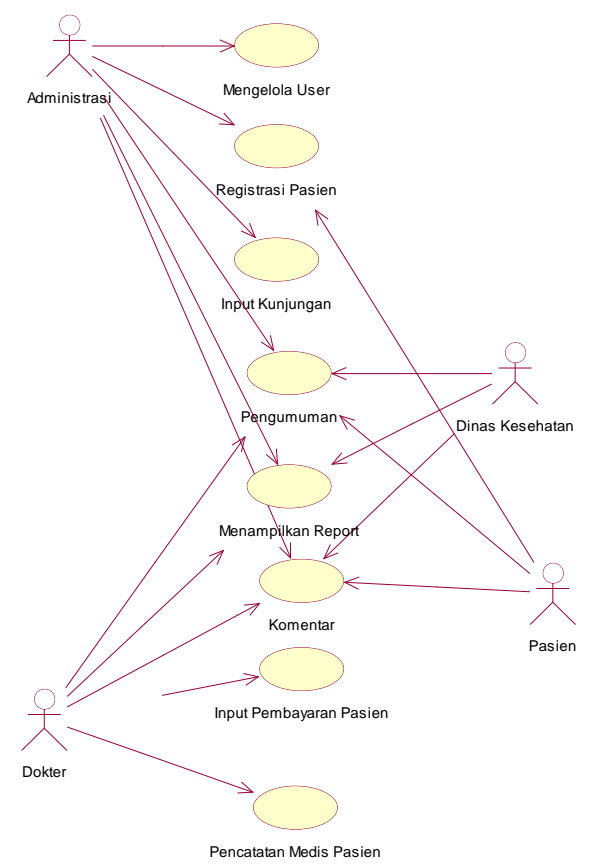

Gambar 2. Use Case Diagram

\section{B. Perancangan Database}

Pembuatan tabel-tabel pada database dibuat dengan menggunakan Microsoft SQL Server 2008.

Dari Gambar 3 dapat dilihat diagram relasi tabel yang menggambarkan relasi antar tabel dan menunjukkan primary key dan foreign key dari tabel-tabel yang dibuat.

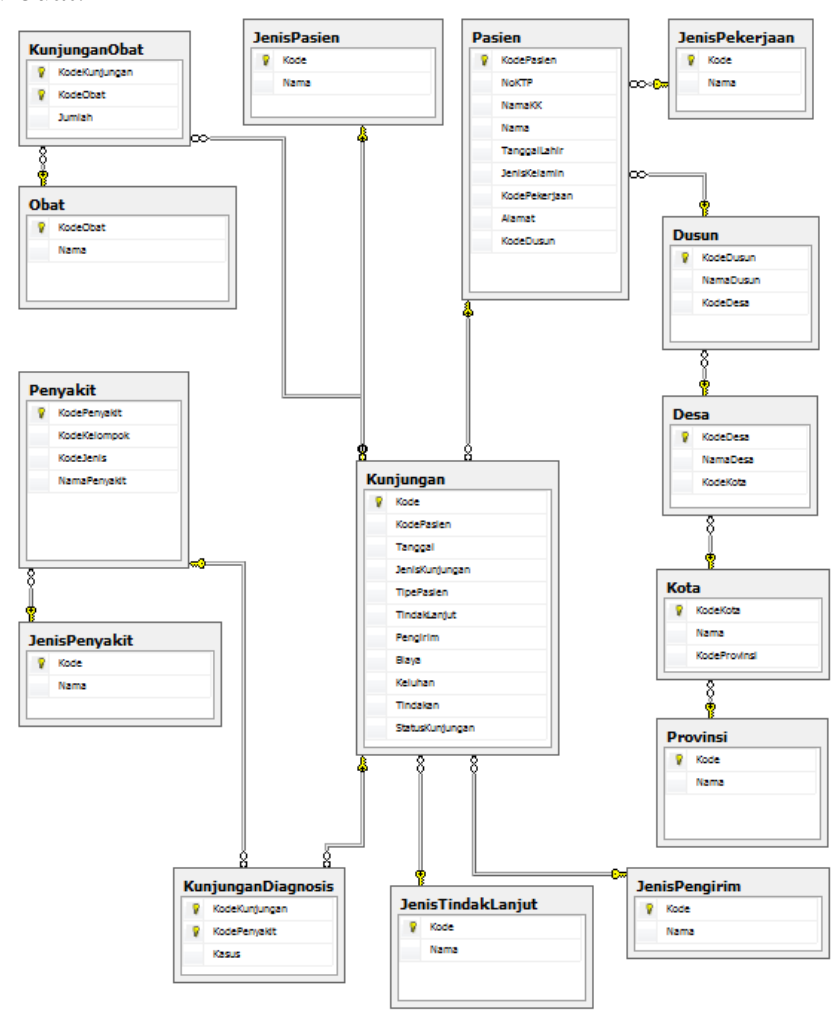



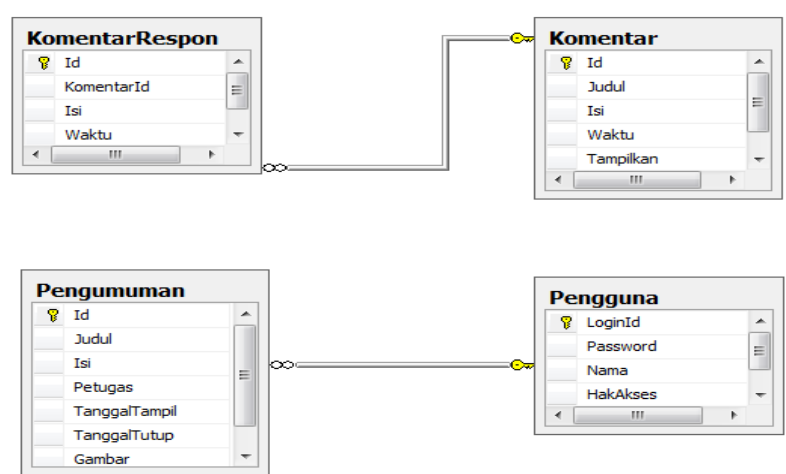

Gambar 3. Diagram Relasi Tabel

\section{Implementasi}

Pada Gambar 4 merupakan halaman utama bernama home page yang akan diakses oleh pengguna saat membuka sistem informasi rekam medis. Terdapat empat fungsi dalam home page, yaitu fungsi pengumuman yang terletak di kiri atas, main menu di sebelah kanan setelah image stetoskop, fungsi login terletak di kanan bawah setelah main menu, dan fungsi komentar yang ada di kiri bawah home page. Fungsi pengumuman digunakan untuk menampilkan pengumuman yang telah dibuat oleh administrasi dan dokter. Fungsi komentar digunakan untuk mengisikan judul dan isi komentar yang dibagian bawah terdapat link kirim untuk menampilkan komentar. Fungsi main menu menunjukan hak akses yang akan diberikan dalam home page, yaitu menu beranda untuk membuka home page dan menu tentang kami untuk melihat profil petugas medis. Fungsi login memiliki dua kolom, kolom pertama untuk mengisikan user name dan kolom kedua untuk mengisikan password. Pada sistem informasi rekam medis pengguna yang dapat melakukan login hanya administrasi, dokter dan dinas terkait, ketiga pengguna tersebut mempunyai hak akses yang berbeda.

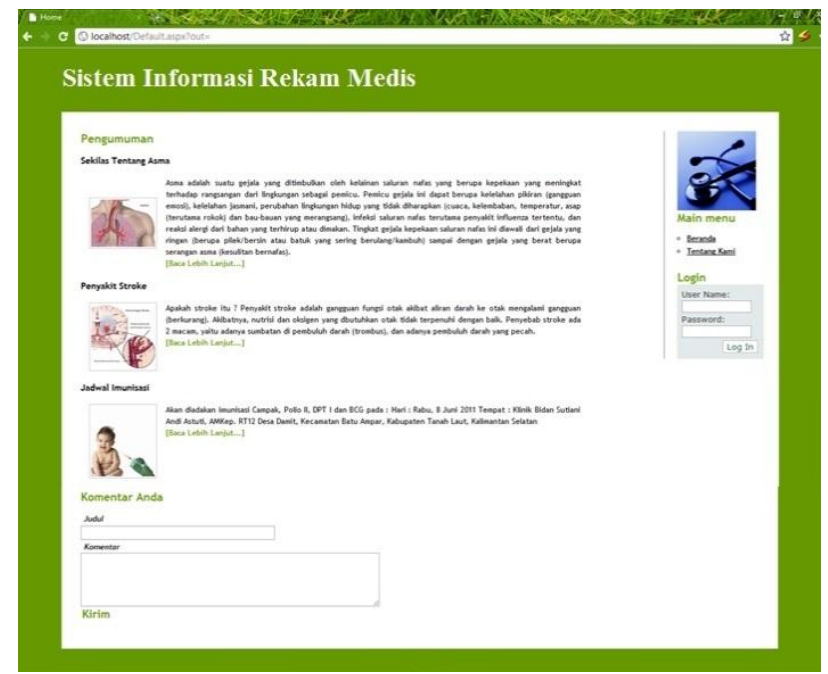

Gambar 4. Home Page

Pada menu tambah pasien, administrasi dapat melakukan registrasi pasien baru yang ditunjukan pada gambar 5 Kolom kode pasien, No. KTP, nama KK, nama pasien, tanggal lahir, dan alamat harus diisi, sedangkan pada kolom jenis kelamin, pekerjaan, Provinsi, Kota/Kabupaten, desa dan dusun, administrasi hanya memilih data yang telah tersedia (contoh input data Wahyu Suprayoga). Tombol submit berfungsi untuk menyimpan data ke dalam database. 


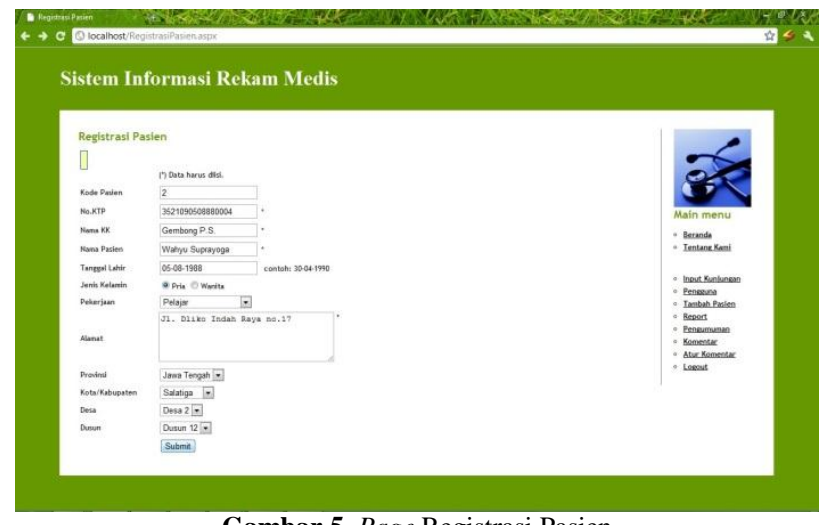

Gambar 5. Page Registrasi Pasien

Setelah memilih pasien, dokter dapat melakukan rekam medis pasien. Gambar 6 menjelaskan cara dokter menuliskan rekam medis. Terdapat kolom pasien, tanggal, jenis kunjungan, jenis pasien, tindak lanjut, pengirim, biaya, dan keluhan yang telah terisi data kunjungan pasien atas nama Wahyu Suprayoga (data sesuai dengan input-an administrasi pada page registrasi pasien). Pada kolom tindak lanjut, tindakan tambahan, biaya, dan keluhan, dokter dapat mengganti data. Setelah memeriksa, dokter mengganti status kunjungan dari antri menjadi selesai atau batal lalu memilih diagnosa sesuai penyakit pasien dan obat yang akan diberikan. Tombol simpan berfungsi untuk menyimpan data rekam medis setelah semua data terisi.

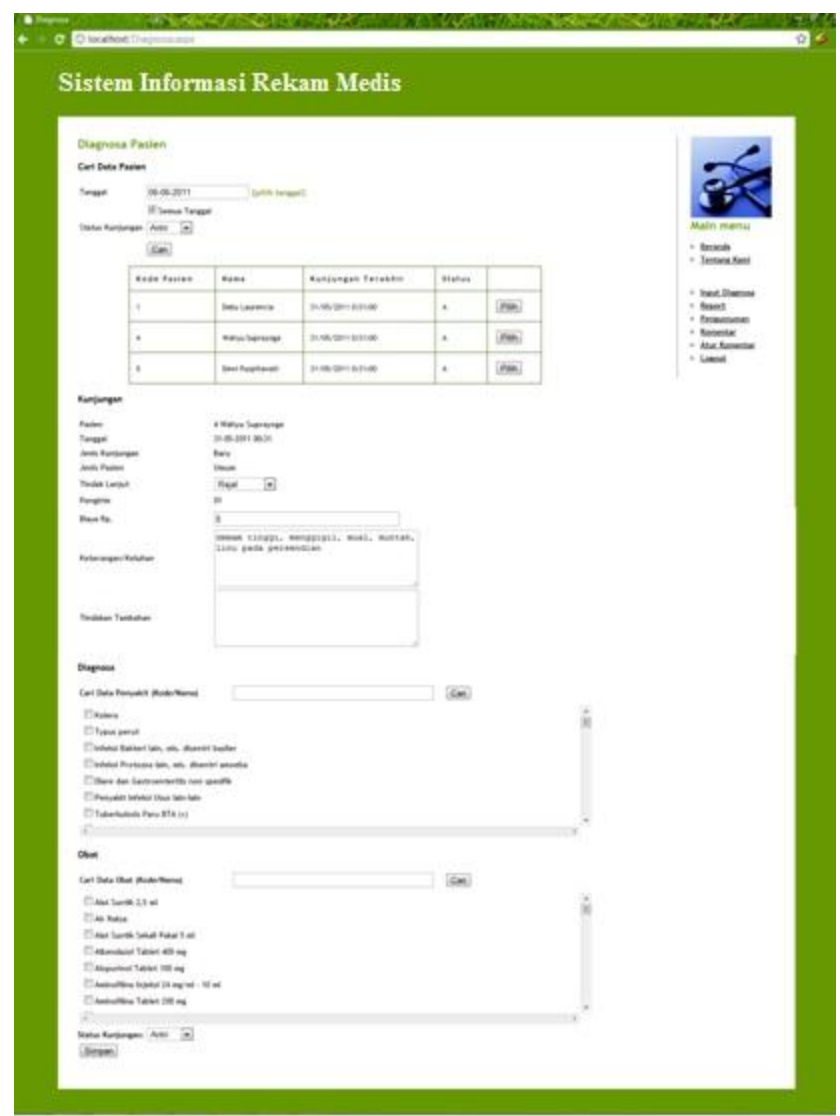

Gambar 6. Page Diagnosa : Rekam Medis

Pada menu history penyakit, administrasi dapat melihat history penyakit berdasarkan nama pasien, seperti ditunjukan pada Gambar 7 dalam hal ini mengambil contoh menampilkan history penyakit pasien bernama Wahyu Suprayoga. Gambar 4.17 menunjukan report history penyakit pasien bernama Wahyu Suprayoga yang telah terisi setelah menjalani pemeriksaan dokter. 


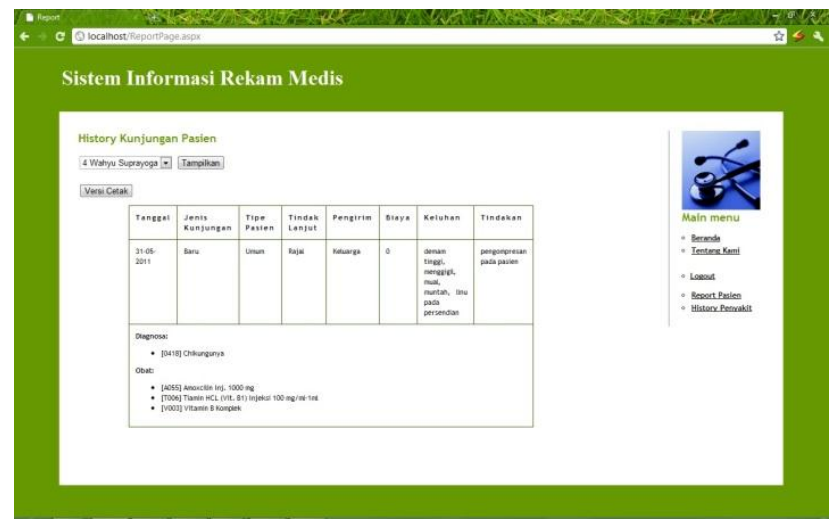

Gambar 7. Page Report : Menampilkan Report History Penyakit

Untuk mencetak report pasien dan report history penyakit, dinas kesehatan dapat menekan tombol versi cetak, lalu tampilan akan berubah seperti pada Gambar 8 .

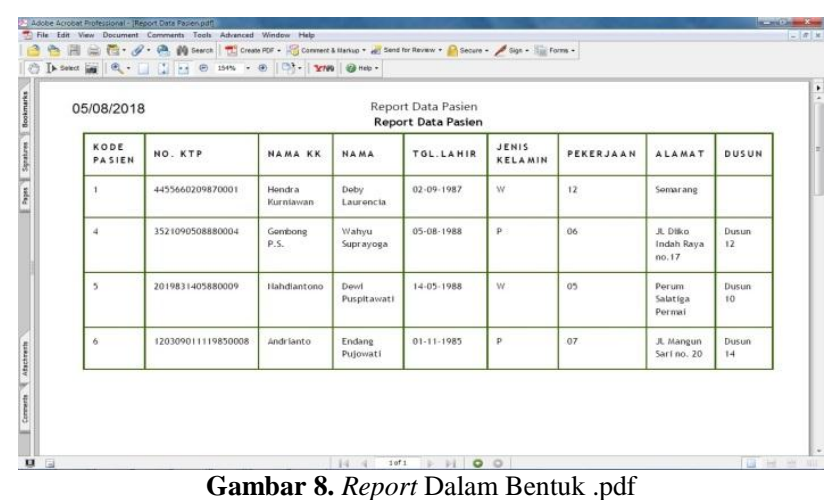

\section{KESIMPULAN}

Sistem informasi rekam medis berbasis web telah berhasil dibangun, dimana secara keseluruhan sistem dapat membantu kinerja administrasi dalam melakukan pendataan pasien, membantu kinerja petugas medis dalam melakukan rekam medis, dan dapat membantu petugas medis dalam membuat laporan tugas-tugasnya.

\section{VI.DAFTAR PUSTAKA}

Buliali, J. L., Suhadi L dan Deddy C. (2007). Sistem Pencatatan Informasi Medis Berbasis Teknologi Microsoft .Net. Jurnal Informatika, Vol. 3, No.1, Juni :97118.

Cahyanti, A.N., Bambang, E.P. (2012). Pembangunan Sistem Informasi Manajemen Puskesmas Pakis Baru Nawangan. Journal Speed - Sentra Penelitian Engineering dan Edukasi - Volume 4 No 4.

Gondodiputro, S. (2007). Rekam Medis dan Sistem Informasi Kesehatan di Pelayanan Kesehatan Primer (Puskesmas), 1, Bagian Ilmu Kesehatan Masyarakat Fakultas Kedokteran Universitas Padjadjaran, Bandung.

Handayani, Tiara., Gerson F. (2016). Perancangan Sistem Informasi Rekam Medis Berbasis Web. Jurnal Teknologi Informasi dan Komputer, Volume 2, Nomor 2, Oktober.

Konsil Kedokteran Indonesia. (2006). Manual Rekam Medis.

Kurniawan. (2010). Cepat Mahir ASP.NET 3.5 untuk Aplikasi Web Interaktif, Yogyakarta:Andi.

Kusumo, A.S., 2004, Visual Basic .NET versi 2002 dan 2003, Jakarta: Elex Media Komputindo.

Laudon, K. C., \& Laudon, J. P. (2010). Management Information System.11th Edition. New Jersey: Pearson Prentice Hall.

Prabowo, D.W.S., Suprihadi dan George J.L.N. (2012). Sistem Informasi Pencatatan Medis Berdasarkan Kode Penyakit ICD 10 Berbasis Web pada Petugas Medis. AITI Jurnal Teknologi Informasi Vol. 9 No. 1 hal. 54-67.

Pressman, Roger S. (2012). Rekayasa Perangkat Lunak - Buku Satu, Pendekatan Praktisi (Edisi 7). Yogyakarta: Andi.

Sundari, J. (2016). Sistem Informasi Pelayanan Puskesmas Berbasis Web. IJSE - Indonesian Journal on Software Engineering. 